\title{
"ENDOCROWN"-An Effective Viable Esthetic Option for Expurgated Endodontically treated Teeth: Two Case Reports
}

\author{
${ }^{1}$ Selvanathan MJ Vinola, ${ }^{2}$ Saravanakarthikeyan Balasubramanian, ${ }^{3}$ Sekar Mahalaxmi
}

\begin{abstract}
Endocrowns are a viable option for the restoration of extensively damaged endodontically treated posterior teeth. The main objective is to achieve a bonded biomimetic reconstruction, i.e., minimally invasive of root canals. The clinical procedure that involves the endocrown fabrication may be considered less complex, more practical, and easier to perform when compared with that of conventional crowns with post and core. This article highlights two different case reports of badly mutilated endodontically treated teeth, effectively managed by means of endocrown-type restorations fabricated with both metal-free and metal ceramicbased prostheses with a 6-month follow-up period.
\end{abstract}

Keywords: Badly mutilated teeth, Biomimetic reconstruction, Endocrown, Esthetics, Pulpless teeth.

How to cite this article: Vinola SMJ, Balasubramanian S, Mahalaxmi S. "ENDOCROWN"-An Effective Viable Esthetic Option for Expurgated Endodontically treated Teeth: Two Case Reports. J Oper Dent Endod 2017;2(2):97-102.

Source of support: Nil

Conflict of interest: None

\section{INTRODUCTION}

The need for replacement of the crown in a grossly mutilated endodontically treated tooth is a challenging task for all clinical practitioners. This might be attributed to various physiological alterations in a root canal treated tooth, including its composition and the remaining dentin macrostructure that predisposes the tooth to numerous risk factors, such as compromised substrate adhesion, reduced retention/ stability, and increased tooth fragility, eventually leading to failure of the prosthesis. ${ }^{1}$ The most commonly recommended treatment option for such cases associated with significant loss of two or more dentin

\footnotetext{
${ }^{1}$ Postgraduate Student (Final Year), ${ }^{2}$ Reader, ${ }^{3}$ Professor and Head

${ }^{1-3}$ Department of Conservative Dentistry and Endodontics, SRM Dental College, SRM University, Ramapuram, Chennai, Tamil Nadu, India

Corresponding Author: Saravanakarthikeyan Balasubramanian Reader, Department of Conservative Dentistry and Endodontics SRM Dental College, SRM University, Ramapuram, Chennai Tamil Nadu, India, Phone: +918939471176, e-mail: skmdc2006@ gmail.com
}

walls is the placement of conventional post and core followed by a crown. ${ }^{2}$ However, there is a need for a definite core filling, particularly in cases of posterior teeth where the masticatory forces are directed parallel to the long axis of the tooth. This is due to the fact that the use of intraradicular posts alone might not contribute to an increased retention of the restoration, as stated in various studies. ${ }^{3}$ In addition, post possesses several disadvantages, such as: (1) It is a techniquesensitive procedure, (2) its placement is limited in case of extremely curved or dilacerated canals, ${ }^{4}(3)$ in case of improper post selection, it might lead to uneven distribution of stresses within the root, thereby leading to tooth fracture and/or post dislodgement, and (4) it requires further removal of healthy sound dentin for its effective placement, which might compromise the root dentin stability in an already weakened tooth, making it more susceptible to fracture. ${ }^{4}$

Endocrown-type restoration, on the contrary, is described as a monolithic (one-piece) ceramic-bonded construction characterized by a supracervical butt joint, retaining maximum enamel to improve adhesion. Though Pissis ${ }^{5}$ was the forerunner of the endocrown technique, it was first described as an adhesive total porcelain endodontic crown that can be fixed to a depulped posterior tooth by Bindl et al. ${ }^{6}$ This specific type of conservative restoration technique uses the pulp chamber space for retention, but not the root canals, thereby favoring effective reconstruction in terms of biomechanics. ${ }^{7}$ It is usually fabricated by using computer-aided milling techniques (computer-aided design/manufacturing ) or by molding ceramic materials under pressure. ${ }^{5,8}$

On careful review of literature, it is observed that endocrowns are fabricated with only ceramic-based restorative materials and their retention is mainly attributed to the resin-dentin adhesive interface. In this light, the present article highlights two different case studies of the effective management of grossly destructed pulpless teeth with endocrowns, fabricated not only by means of a metal-free zirconium oxide $\left(\mathrm{ZrO}_{2}\right)$ based restoration but also a metal ceramic-based porcelain-fused-to-metal (PFM) prosthesis, based on the remaining tooth structure and the patient needs, however, with minor retentive modifications done in the tooth preparation. 


\section{CASE REPORTS}

\section{Case 1}

A 45-year-old female reported to our department with a chief complaint of dislodged crown in relation to lower left back tooth region. Patient gave a history of root canal treatment done on the same tooth 3 weeks back in a private clinic. Her medical history was noncontributory. Clinical examination revealed an extensive destruction of tooth structure $(>50 \%)$ following the removal of coronal restoration. However, the patient was asymptomatic and an intraoral periapical (IOPA) radiograph in relation to 47 revealed a satisfactory obturation without any evidence of periapical rarefaction (Figs 1A and B). Therefore, reintervention (Re-Rct) was not attempted and various postendodontic treatment options were considered and proposed according to the patient's request for minimal treatment cost. Due to the presence of only half the residual tooth structure, a conservative postendodontic management with an endocrown was suggested and the treatment was executed following the patient consent.

\section{Clinical Procedure for Metal-free Zirconia-based Ceramic Endocrown in 47}

The tooth preparation was done according to the technique recommended by Bindl and Mörmann. ${ }^{9}$ The cervical margins were leveled in the shape of a chamfer with a diamond bur SO-21 (Dia-Burs, Mani) at high speed and under constant cooling system throughout the procedure ensuring that an uniform thickness of 1.5 $\mathrm{mm}$ was maintained with the remaining coronal tooth structure (Fig. 1B). The bur was oriented along the long axis of the tooth and maximum efforts were attempted to maintain an occlusal convergence of 7 to $10^{\circ}$ to ensure a continuous flow of the prepared coronal pulp chamber and the access cavity.

Following opening of the root canal, the gutta-percha was removed up to $2 \mathrm{~mm}$ below the level of each orifice, followed by complete sealing of the coronal orifices and the pulp chamber ( $2 \mathrm{~mm}$ thick) with glass ionomer (Type II) restorative cement (GC corporation Tokyo, Japan), as shown in Figure 1C. The chamfered walls and margins were then smoothed with a finishing bur TR21EF (Dia-Burs, Mani). Gingival retraction cord 00 (Ultracord, Dent One Inc, USA) was applied along the gingival crevice and an impression was made with poly(vinyl siloxane) material (Aquasil LV, Dentsply DeTrey, Germany) using a putty wash technique (Fig. 1D) and was sent to the laboratory for further processing. Temporization was done with Luxatemp Automix Plus resin (DMG, America) to maintain the dimensions of the prepared tooth in the interappointment period. In the subsequent appointment, following the evaluation of final fit of fabricated $\mathrm{ZrO}_{2}$-based ceramic endocrown in 47, final cementation was done with self-adhesive resin composite (Variolink N Dual-cure, Ivoclar Vivadent, Liechtenstein) under adequate isolation control (Figs 1E-G), preceded by appropriate surface treatment techniques, such as abrasion with diamond bur followed by acid etching (typically with hydrofluoric acid, HF). The patient was then reviewed after 6 months (Fig. 1H).

\section{Case 2}

A 32-year-old female reported to our department with a chief complaint of dislodged restoration in relation to lower right back tooth region. Patient gave a history of root canal treatment done on the same tooth 5 days back in a private clinic and her medical history was noncontributory. Clinical examination revealed an extensive destruction of coronal tooth structure $(>50 \%)$ following the complete removal of temporary restoration. However, the patient was asymptomatic and an IOPA radiograph in relation to 46 revealed a satisfactory root canal filling without any evidence of periapical lesion (Figs 2A and 2B). The case 2 was similar to that of case 1 , but due to patient's severe economic constraint and based on her demands, a conservative postendodontic management with a metal ceramic-based endocrown (PFM) was suggested and the treatment was carried out after obtaining a written consent from the patient. The preparation design for the endocrown in the present case was similar to that of case 1 ; however, certain modifications were incorporated in the tooth preparation to aid in the retention of this PFMbased endocrown in 46 .

In the present case, retentive grooves ( $1 \mathrm{~mm}$ deep) were placed on the buccal and lingual axial surfaces of the external aspect of the tooth, so as to aid in mechanical retention and stability of the endocrown (Fig. 2C). Also, sandblasting of the fabricated PFM endocrown was done to enhance the retention of this conservative single piece restoration followed by luting of the final finished PFMbased endocrown with glass ionomer cement (GIC Type II, GC corporation Tokyo, Japan) under proper isolation (Figs 2D-I). The patient was then recalled after 6 months (Fig. 2J).

\section{DISCUSSION}

In today's adhesive dentistry era, endocrown can be considered as a viable, conservative, and feasible alternative to conventional post and core restorations. The endocrown is fixed to a depulped posterior tooth, which is anchored to the internal portion of the pulp chamber and to the cavity margins, thus obtaining macromechanical retention (provided by the pulpal walls), and microretention (by adhesive cementation). ${ }^{9,10}$ In addition, its easier 

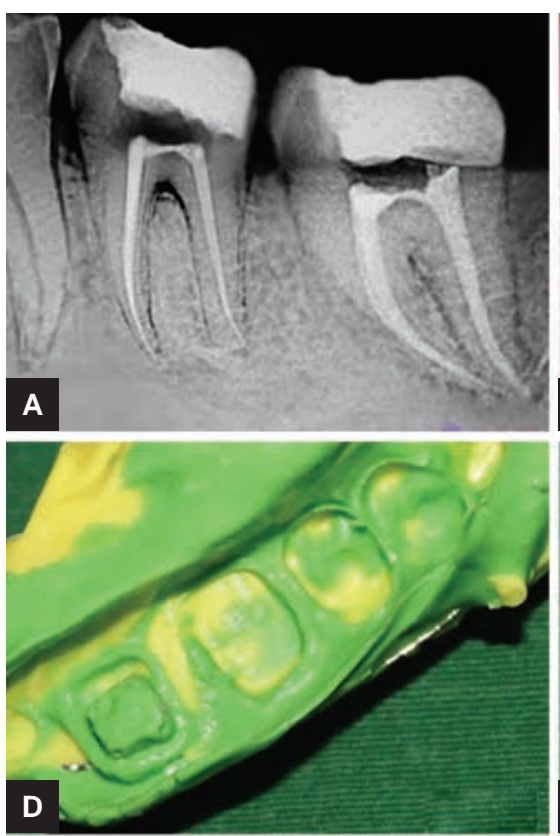

B
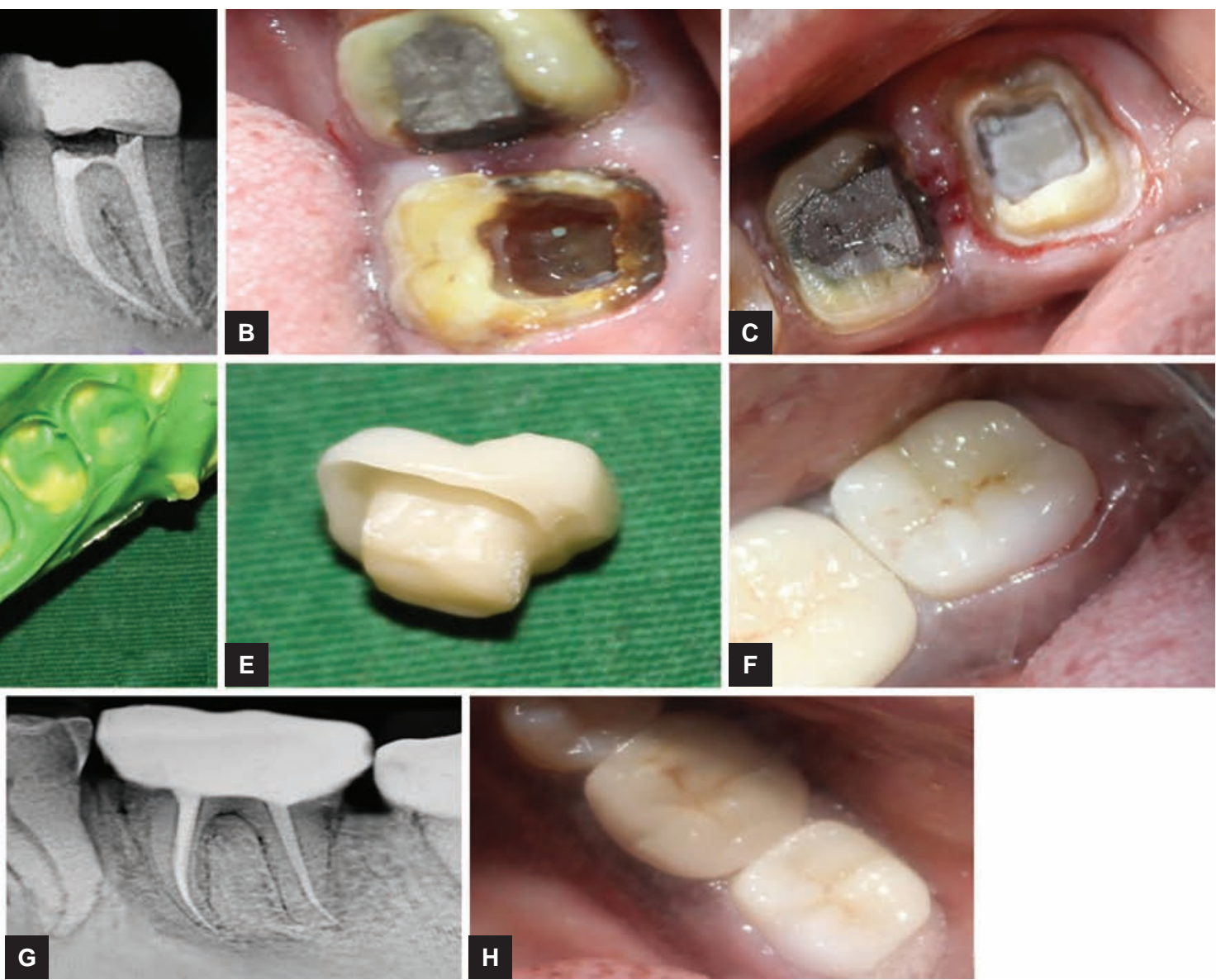

Figs $1 \mathrm{~A}$ to $\mathrm{H}$ : CASE 1-Metal-free zirconia $\left(\mathrm{ZrO}_{2}\right)$ based endocrown prosthesis: (A) Preoperative IOPA radiograph of 47 ; (B) tooth preparation for metal-free $\mathrm{ZrO}_{2}$ based endocrown in 47; (C) sealing of the intracanal orifices and pulp chamber with GIC (Type II); (D) final impression with polyvinyl siloxane material; $(E)$ fabricated zirconia-based endocrown; $(F)$ final cementation of biomimetic endocrown in 47; (G) postoperative IOPA of 47 with cemented zirconia-based ceramic endocrown in place; and $(\mathrm{H})$ postoperative review following 6 months

technique, less clinical time, and better acceptance make it a superior option among the various treatment alternatives. ${ }^{11}$ The overall success rate of the endocrowns is very good, and the clinical concept also appears to be simple and feasible, as stated by Bindl et al. ${ }^{6}$ In an another 2-year evaluation clinical study, Bernhart et $\mathrm{al}^{12}$ concluded that endocrowns represent a very promising treatment alternative for endodontically treated molars. ${ }^{13}$

The endocrown fits perfectly with the concept of biointegration and can be the preferred choice for restoring posterior endodontically treated and badly destructed teeth. Endocrowns are especially indicated in cases of molars with short, obliterated, dilacerated, fragile roots, and severely mutilated tooth ${ }^{13}$ and also in situations, where there is an extensive loss of coronal tooth structure $^{1}$ (i.e., $\geq 1 / 2$ residual tooth structure) associated with limited interocclusal space, ${ }^{13}$ in which it is not possible to attain an adequate thickness of the ceramic covering on the metal or ceramic substructures, as in the present cases (cases 1 and 2).

The main advantages of $\mathrm{ZrO}_{2}$ which was first introduced by Martin Heinrich Klaproth ${ }^{14}$ (1789) include (1) noncytotoxicity, (2) highly inert and insolubility in fluids,
(3) chemical and dimensional stability, (4) radiopacity, (5) high mechanical strength, (6) increased toughness and elasticity, and (7) no potential of bacterial adhesion. ${ }^{15,16}$ Based on these material properties, it is expected that $\mathrm{ZrO}_{2}$-based prostheses are able to withstand high masticatory loads and stresses, in addition to the replacement of tooth form and function, including esthetics.

Though a potential problem of zirconia application in restorative dentistry is its adhesion to different substrates, it can be overcome by conventional surface treatment techniques, such as acid etching (with HF) and abrasion with diamond rotary instrument, which might have resulted in enhanced bonding (as in case 1). Various alternative surface treatment techniques available for $\mathrm{ZrO}_{2}$ include selective infiltration etching (SIE) and laser (erbiumdoped yttrium aluminum garnet laser and neodymiumdoped yttrium aluminum garnet laser) application. ${ }^{17-19}$ The SIE is a novel surface roughening technique that has been explored specifically for $\mathrm{ZrO}_{2}$, which uses a heatinduced maturation process to prestress surface grain boundaries in $\mathrm{ZrO}_{2}$ to allow infiltration of boundaries with molten glass. The glass is then etched out using HF, creating a network of inter-granular porosity that allows 


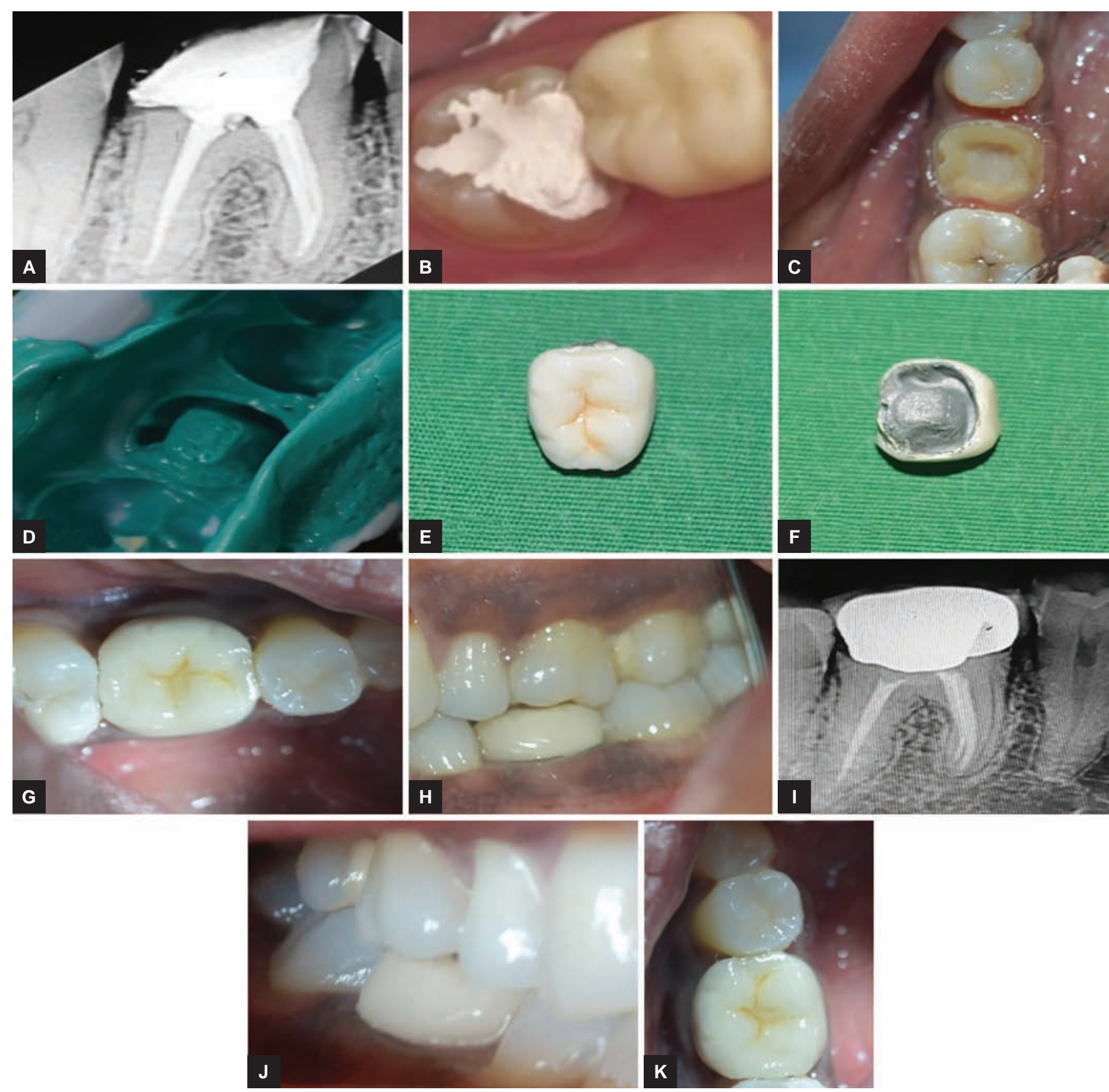

Figs 2A to J: CASE 2-Metal ceramic-based (PFM) endocrown prosthesis: (A) Preoperative IOPA of 46; (B) temporary coronal restoration in 46; (C) coronal seal achieved with GIC (Type II) following tooth preparation (with incorporated secondary retentive grooves on the buccal and lingual axial walls on the external aspect) in 46; (D) final impression with polyvinyl siloxane material; (E) fabricated PFM endocrown; (F) inner surface of the metal ceramic-based endocrown prosthesis; (G) final cementation of PFM endocrown in 46; (H) postoperative assessment; (I) postoperative IOPA of 46 with cemented PFM-based endocrown in place; and (J) postoperative review following 6 months

for nano-mechanical interlocking of resin cement, thereby aiding in enhanced bonding, as stated by, Casucci et al. ${ }^{20}$

In case 2, a PFM-based endocrown was planned and executed based on the patient's economic factors. Though microretention is compromised in PFM endocrown case, meticulous care was followed to enhance the retention of the restoration by incorporation of secondary retentive grooves in the axial walls in addition to the sandblasting of the metal surface before cementation, as stated in various studies. ${ }^{21}$ These grooves aid in retention of the metal surface onto the tooth accompanied by the luting cement by reducing the radius of rotation. Grooves not only enhance the retention by presenting additional nearparallel sided walls to the preparation, but also limit the path of insertion. ${ }^{15}$ Also, resistance feature is improved by the antirotational design of the preparation. ${ }^{15}$ Though they are used mainly for metal and metal-ceramic restorations but are generally impractical for all ceramic crowns, as stated by Blair et al. ${ }^{22}$ Various other secondary retentive factors, such as pins, boxes, slots, ${ }^{23}$ can also be 
considered in such cases in a clinical scenario. In addition, sandblasting was also done in PFM endocrown case (case 2) to enhance the bonding, whereas it was not done in zirconia endocrown case (case 1), as it might lead to an adhesive failure due to compromised bonding, as stated in a study by Aboushelib et al. ${ }^{23}$

Additionally, in both the tooth preparations, the cervical margins were leveled in the shape of a chamfer throughout the entire extension of the crown and root remainders, maintaining the lingual face terminal in enamel, with an intention of providing greater bond quality and enhanced retention, as stated by Biacchi et al. ${ }^{14}$ The preparation inside the pulp chamber might also have promoted the mechanical retention and stability of the endocrown. The gutta-percha was removed up to $2 \mathrm{~mm}$ in the pulp canal, so as to take advantage of the saddle-like anatomy of the cavity floor, whereas GIC placement in the pulp chamber is a biomimetic concept which creates adequate preparation geometry by filling internal undercuts, thereby attributing to improved marginal seal in the present cases. $^{13}$

However, endocrowns are contraindicated in the following cases: (1) Where the pulp chamber depth is less than $3 \mathrm{~mm}$ or cervical margin is less than $2 \mathrm{~mm}$ wide, (2) if adhesion cannot be assured, and (3) presence of only negligible remaining tooth structure. ${ }^{24}$ In addition, the differences in the modulus of elasticity between the harder ceramic and dentin might lead to risks of debonding and root fracture. Hence, case selection is very important and critical for the long-term success of the endocrown-type restoration. The success and longevity of endocrowns also depend upon various other factors, such as operator skill, appropriate preparation techniques, adequate selection of most suitable ceramic options, and the choice of bonding material. In certain situations, endocrown has been rejected as a treatment option because of the lack of adhesive bonding and patients' economical constraint, as the main criteria. In such cases, porcelain fused to metal-based endocrowns (as in case 2) can be considered as a promising alternative, however, with appropriate incorporation of retention and resistance features in the tooth preparation (as mentioned in case 2).

In the current case studies, temporization during interappointment period was done with Luxatemp Automix Plus resin. The crowns using metal and integral ceramics, which faithfully reproduce the natural form of the tooth, require an adequate thickness that respects the dental anatomy, causing the exposure of millions of dentinal tubules. These tubules may act as potential pathways for the diffusion and colonization of bacteria. ${ }^{25}$ Therefore, an adequate protection of the prepared tooth surfaces is mandatory while the prosthesis is being made for the long-term success of the therapy. Provisional restoration fixed by means of provisional cement offers an acceptable retention and prevents tooth fracture and microleakage, thereby restoring form and function, in addition but not limited to, acceptable esthetics, and to a certain degree of marginal seal maintaining the dimensions of the prepared tooth. $^{26}$

The provisional coronal restoration is often intended for diagnostic and therapeutic purposes, being a test structure where all the necessary functional, occlusal, and esthetic adjustments can be carried out to optimize incorporation of the definitive prosthesis. From a clinical standpoint, coronal exposure of the root canal obturation to saliva for a relatively short period of time (30 days or more) might be considered as an indication for retreatment. ${ }^{27,28}$ In the present case reports, the patients reported to us within 15 days following endodontic treatment of the concerned tooth for a definitive final restorative prosthesis. In addition, there were no signs and symptoms (clinically) associated with the absence of any significant periapical rarefaction (radiographically) and their reluctance for retreatment can all be considered as potential determinants for our direct execution of postendodontic treatment plan without any reintervention.

\section{CONCLUSION}

Endocrowns appear to be a promising treatment option for endodontically treated posterior teeth with extensive loss of coronal tooth structure associated with limited interocclusal space based on the patient's affordability and esthetic demands. However, metal ceramicbased endocrowns (PFM) might also be considered as a valuable treatment alternative, particularly in patients in whom economical constraint is a limiting factor. All the aforestated clinically significant factors should be analyzed before considering PFM-based endocrown in clinical situations, to achieve promising results. This simple and efficient concept is more compatible with the philosophy of biointegrated prostheses, and hence, this type of reconstruction, which is still uncommon, should be more widely known and used in restorative dentistry.

\section{REFERENCES}

1. Hargreaves KM.; Berman LH. Cohen's pathways of the pulp expert consult-e-book. 11th ed. St. Louis (MO): Elsevier Inc (Elsevier Health Sciences); 2015.

2. Schwartz RS, Robbins JW. Post placement and restoration of endodontically treated teeth: a literature review. J Endod 2004 May;30(5):289-301.

3. Ma PS, Nicholls JI, Junge T, Philips KM. Load fatigue of teeth with different ferrule lengths, restored with fiber posts, composite resin cores, and all-ceramic crowns. J Prosthet Dent 2009 Oct;102(4):229-234. 
4. Trope M, Maltz DO, Tronstad L. Resistance to fracture of restored endodontically treated teeth. Available from: Dent Traumatol 1985 Jun 1;1(3):108-111.

5. Pissis P. Fabrication of a metal-free ceramic restoration utilizing the monoblock technique. Pract Periodontics Aesthet Dent 1995 Jun-Jul;7(5):83-94.

6. Bindl A, Richter B, Mörmann WH. Survival of ceramic computer-aided design/manufacturing crowns bonded to preparations with reduced macro retention geometry. Int J Prosthodont 2005 May-Jun;18(3):219-224.

7. Slangen P.; Corn S.; Fages M.; Cuisinier FJ. Prosthodontic crown mechanical integrity study using Speckle Interferometrie. In: Osten W, Kujawinska M, editors. Fringe 2009: 6th international workshop on advanced optical metrology. Berlin, Heidelberg: Springer; 2009. p. 734.

8. Mrazek WR. Laboratory procedures for fabricating pressable all-ceramic restorations. J Dent Technol 1997 May;14(4):10-16.

9. Bindl A, Mörmann WH. Clinical evaluation of adhesively placed Cerec endo-crowns after 2 years - preliminary results. J Adhes Dent 1999 Autumn;1(3):255-65.

10. Valentina V, Aleksandar T, Dejan L, Vojkan L. Restoring endodontically treated teeth with all-ceramic endo-crowns: case report. Serbian Dent J 2008 Jan;55(1):54-64.

11. Lander E, Dietschi D. Endocrowns: a clinical report. Quintessence Int 2008 Feb;39(2):99-106.

12. Bernhart J, Bräuning A, Altenburger MJ, Wrbas KT. Cerec3D endocrowns-two-year clinical examination of CAD/CAM crowns for restoring endodontically treated molars. Int J Comput Dent 2009 Dec;13(2):141-154.

13. Amal S, Nair MG, Sreeja J, Babu A, Ajas A. Endocrown an overlooked alternative. Arch Dent Med Res 2016;2(1): 34-38.

14. Biacchi GR, Mello B, Basting RT. The endocrown: an alternative approach for restoring extensively damaged molars. J Esthet Restor Dent 2013 Dec;25(6):383-390.

15. Raigrodski AJ. Contemporary materials and technologies for all-ceramic fixed partial dentures: a review of the literature. J Prosthet Dent 2004 Dec;92(6):557-562.

16. Dion I, Rouais F, Baquey C, Lahaye M, Salmon R, Trut L, Cazorla JP, Huong PV, Monties JR, Havlik P. Physico-chemistry and cytotoxicity of ceramics. J Mater Sci Mater Med 1997 May;8(5):325-332.

17. Scotti R, Kantorski KZ, Monaco C, Valandro LF, Ciocca L, Bottino MA. SEM evaluation of in situ early bacterial colonization on a Y-TZP ceramic: a pilot study. Int J Prosthodont 2007 Jul-Aug;20(4):419-422.

18. Atsu SS, Kilicarslan MA, Kucukesmen HC, Aka PS. Effect of zirconium-oxide ceramic surface treatments on the bond strength to adhesive resin. J Prosthet Dent 2006 Jun;95(6): 430-436.

19. Piascik JR, Swift EJ, Thompson JY, Grego S, Stoner BR. Surface modification for enhanced silanation of zirconia ceramics. Dent Mater 2009 Sep;25(9):1116-1121.

20. Usumez A, Hamdemirci N, Koroglu BY, Simsek I, Parlar O, Sari T. Bond strength of resin cement to zirconia ceramic with different surface treatments. Lasers Med Sci 2013 Jan;28(1): 259-266.

21. Casucci A, Osorio E, Osorio R, Monticelli F, Toledano M, Mazzitelli C, Ferrari M. Influence of different surface treatments on surface zirconia frameworks. J Dent 2009 Nov;37(11): 891-897.

22. Blair FM, Wassell RW, Steele JG. Crowns and other extracoronal restorations: preparations for full veneer crowns. Br Dent J 2002 May;192(10):561-571.

23. Aboushelib MN, de Jager N, Kleverlaan CJ, Feilzer AJ. Microtensile bond strength of different components of core veneered all-ceramic restorations. Dent Mater 2005 Oct;21(10):984-991.

24. Gilboe DB, Teteruck WR. Fundamentals of extracoronal tooth preparation. Part I. Retention and resistance form. J Prosthet Dent 1974 Dec;32(6):651-656.

25. Fages M, Bennasar B. The endocrown: a different type of all-ceramic reconstruction for molars. J Can Dent Assoc 2013 Oct;79:d140.

26. Goldman M, Laosonthorn P, White RR. Microleakage-full crowns and the dental pulp. J Endod 1992 Oct;18(10):473-475.

27. Baldissara P, Comin G, Martone F, Scotti R. Comparative study of the marginal microleakage of six cements in fixed provisional crowns. J Prosthet Dent 1998 Oct;80(4):417-422.

28. Siqueira JFJr. Aetiology of root canal treatment failure: why well-treated teeth can fail. Int Endod J 2001 Jan;34(1):1-10. 